\title{
Taste thresholds of patients in an NHS elderly care ward
}

\author{
S. Behrman ${ }^{1}$, K. Lau ${ }^{2}$, M. A. Gosney ${ }^{3}$, O. B. Kennedy ${ }^{2}$ and L. Methven ${ }^{2}$ \\ ${ }^{1}$ Royal Berkshire NHS Foundation Trust, Reading RGI 5AN, UK, ${ }^{2}$ Department of Food and Nutritional Sciences and \\ ${ }^{3}$ Clinical Health Sciences, University of Reading, Reading RG6 6AP, UK
}

Taste thresholds are known to increase with age ${ }^{(1)}$, illness ${ }^{(2)}$ and medication ${ }^{(3)}$. Decline in taste and olfaction which leads to increased thresholds, have been linked to a loss of interest in food, reduced food intake and under-nutrition ${ }^{(3)}$. Although bitterness has been cited by some authors to be most affected ${ }^{(4)}$, the other taste thresholds also increase. Comparing older and younger cohorts, detection thresholds have previously been found to be 3.8 and 2.4 times higher for salt and sweet ${ }^{(1)}$ and 2.8 times higher for umami (glutamate) ${ }^{(5)}$. In a previous study by the authors, elderly hospital patients were found to have higher sweet taste thresholds than elderly free-living volunteers, mean sucrose thresholds of these cohorts were 8.8 and $16.1 \mathrm{mMol}$, respectively ${ }^{(6)}$.

In the present study, four taste thresholds were examined using an alternative forced choice method in NHS hospital patients ( $n$ 17, age range 73-93, mean 84). The concentration ranges used were as follows: salt (sodium chloride) $0.4-32.8 \mathrm{mMol}$, sweet (sucrose) 2.0-31.8 mMol, umami (monosodium glutamate) $0.4-32.8 \mathrm{mMol}$ and bitter (quinine sulfate) $0.003-0.125 \mathrm{mMol}$ (the geometric progression of each sequence were $3,2,3$ and 2.5 , respectively). The mean and range for each taste detection threshold are given in Table 1 .

Table 1. Taste detection thresholds (mMol) of older hospitalised patients

\begin{tabular}{lcccc}
\multicolumn{4}{c}{ Table 1. Taste detection thresholds $(\mathrm{mMol})$} & of older hospitalised patients \\
\hline & $\begin{array}{c}\text { Salt } \\
\text { (sodium chloride) }\end{array}$ & $\begin{array}{c}\text { Sweet } \\
\text { (sucrose) }\end{array}$ & $\begin{array}{c}\text { Umami } \\
\text { (monosodium glutamate) }\end{array}$ & $\begin{array}{c}\text { Bitter } \\
\text { (quinine sulfate) }\end{array}$ \\
\hline Mean $^{\mathrm{a}}$ & 29.8 & 15.9 & 7.2 & 0.030 \\
Minimum & 6.3 & 2.0 & 0.4 & 0.002 \\
Maximum & $>33$ & $>11$ & $>32$ & $>0.1$ \\
\hline${ }^{a}$ Geometric mean of individual thresholds, where individual taste thresholds were taken as the geometric mean between
\end{tabular}

the concentration of the first correctly identified solution and the previous lower concentration.

As expected, the mean bitter threshold was the lowest of the four taste thresholds recorded and the umami (glutamate) threshold was lower than the salt threshold. Correlation analysis (pearson) indicated a slight correlation between the umami thresholds and the bitter $(r=0.56, P=0.03)$ and sweet $(r=0.58, P=0.02)$ thresholds. The mean sweet threshold was very similar to that found in the author's previous patient study ${ }^{(6)}$. The sodium chloride and glutamate thresholds were similar to values found in older adults in a previous study, where the mean detection thresholds of healthy older adults ( $n$ 10, age range 70-79, mean 75) were 19 and 6 mMol, respectively, in comparison to lower mean values of 3 and $2 \mathrm{mMol}$, respectively, in younger adults $\left(n\right.$ 13, age range 18-22, mean 20) ${ }^{(7)}$. Further work will determine whether the thresholds of individuals in the present study are related to their medication, disease state and blood $\mathrm{Zn}$ levels. The current finding may identify physiological differences in taste thresholds as a result of ageing and/or changes due to disease states and medication; from this, it may be possible to develop food products to make them more appealing to certain subgroups of the population.

This study was sponsored by Research into Ageing.

1. Bales CW et al. (1986) Am J Clin Nutr 44, 664-669.

2. Schiffman SS (2007) Proc Nutr Soc 66, 331-345.

3. Nolan NM (2001) Nutr Clin Care 4, 43-52.

4. Murphy C \& Gilmore MM (1989) Percept Psychophys 45, 121-128.

5. Schiffman SS (1994) Physiol Behav 56, 265-275.

6. Methven L et al. (2010) Proc Nutr Soc (In the Press).

7. Schiffman SS et al. (1990) Chem Senses 15, 671-678. 